\title{
CARCINOMATOSE MENINGEA
}

\author{
MilberTo SCAFF* \\ DANIELE RIVA** \\ Wilma S. O. Fernandes *
}

$\mathrm{Na}$ earcinomatose das meninges estas estruturas são difusamente invadidas pelo tecido neoplásico e freqüentemente só o exame microscópico revela a natureza do processo patológico. A sobrevida, após o início dos sintomas neurológicos, varia de 3 a 5 meses; ocasionalmente há sobrevida acima de 8 meses 3 .

As manifestações podem ser de vários tipos: 1) sindrome de irritação meníngea; 2) sintomas devidos ao comprometimento do sistema nervoso central e/ou dos nervos espinais; 3) alterações psiquicas variáveis, geralmente com excitação nas fases iniciais e a apatia e sonolência na fase terminal; 4) paralisia de nervos cranianos, especialmente os relacionados com a motricidade extrinseca ocular; 5) síndrome de cauda eqüina ${ }^{1}$. A cefaléia, muitas vêzes, é o primeiro sintoma; em alguns casos, especialmente naqueles em que a afecção predomina ao nível das meninges espinais, o quadro pode iniciar-se com dor na região dorsal e nos membros. A cefaléia em geral é acompanhada de edema de papila, que pode ser devido a aumento de pressão intracraniana ou ao envolvimento dos nervos e quiasma óptico pelo tecido neoplásico ${ }^{6}$.

No líquido cefalorraqueano (LCR) com freqüência há aumento do teor de proteínas, diminuição do teor de glicose e hipercitose com predominância de linfomonucleares; a presença de células neoplásicas depende da existência de relações diretas das massas neoplásicas com os reservatórios de LCR. Células neoplásicas são mais comumente encontradas nos casos de tumores metastáticos do que nos primitivos; elas podem apresentar-se isoladas ou agrupadas; seu tamanho é avantajado (20 micra ou mais), seu citoplasma pode ser basófilo. Elas contêm um ou mais núcleos, de tamanho variável, nos quais se evidenciam nucléolos e cromatina grosseiramente granulosa 4 .

Benson ${ }^{2}$ admite que as metástases alcançam o sistema nervoso pelas seguintes vias: 1) hematogênica; 2) linfática, as células tumorais ascendendo através do sistema linfático, envolvendo os nervos periféricos e inva-

Departamentos de Neurologia (Prof. Adherbal Tolosa) e de Anatomia e Fisiologia Patológicas (Prof. Constantino Mignone) da Faculdade de Medicina da Universidade de São Paulo: * Médicos Assistentes; ** Médico Residente. 
dindo o espaço sub-aracnóideo; 3) difusão pelo sistema venoso vertebral. A difusão do processo no espaço sub-aracnóideo parece ser ocasionada pela fixação de células neoplásicas veiculađas pelo LCR.

\section{O B S E R V A C A}

J.M., com 45 anos de idade, sexo masculino, internado em 15-1-1969 (Reg. G. 870.158). O paciente passava bem até há 18 meses, quando começou a apresentar pertinaz constipação intestinal e dores abdominais mal caracterizadas, mais intensas ao nivel do hipocôndrio direito e epigástrico; ao mesmo tempo foi notando progressivo emagrecimento, chegando a perder 30 quilos de pêso nos primeiros 12 meses da doença. Neste periodo procurou o Hospital das Clínicas, sendo internado em enfermaria de Clínica Médica em 31-5-1968. Durante a internação foi submetido a exploração clínica, radiológica e laboratorial sem que fôsse possível chegar a um diagnóstico definitivo. O paciente teve alta, continuando com irregularidades no trânsito intestinal e perda de pêso. Nos primeiros dias de 1969 começou a ter parestesias na parte distal dos 4 membros e fraqueza muscular ao nivel dos membros inferiores, depois apresentou queda da palpebra direita $\mathrm{e}$ diplopia. Exame físico geral - Paciente intensamente emagrecido, desidratado e com micropoliadenopatia generalizada. Palpação profunda do abdômen bastante dolorosa. Exame neurológico - Paciente orientado no tempo e no espaço, colaborando no exame. Paraparesia crural flácida, arreflexia profunda nos membros inferiores, reflexos profundos nos membros superiores mais nítidos à direita. Reflexos cutâneo-plantares em flexão. Hipotrofia ao nivel dos membros inferiores. Hipoestesia tátil e dolorosa no $1 / 3$ distal e artrestesia abolida nos MMII. Paralisia completa do $3 .^{\circ}$ nervo craniano à direita. Exames complementares - Exame do liquido cefalorraqueano: punção lombar; pressão inicial 16, pressão final 2 após

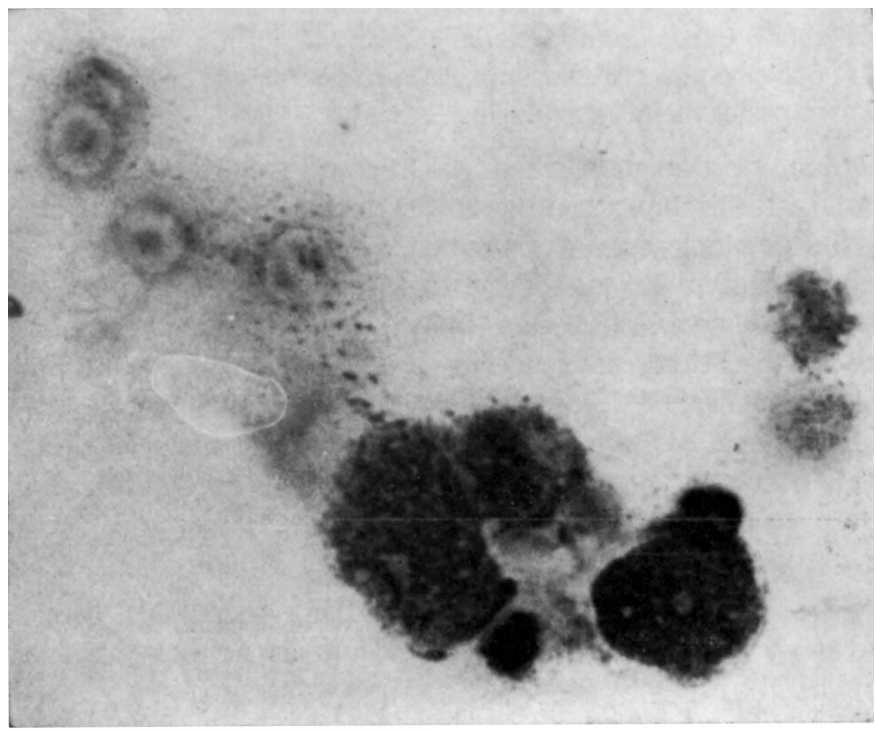

Fig. 1 - Caso J.M. Células neoplásicas no líquido cefalorraqueano. 

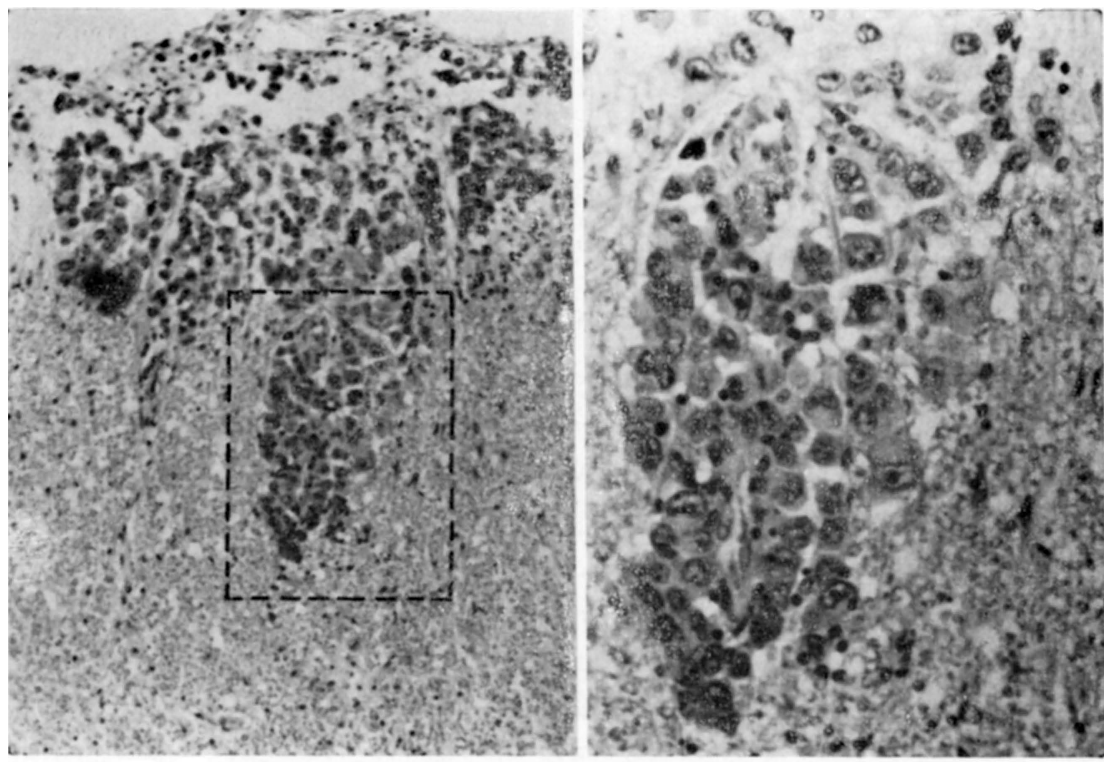

Fig. 2 - Caso J.M. À esquerda, corte de medula espinal com infiltração neoplásica das leptomeninges e do tecido nervoso; à direita, aumento maior da parte assinalada.

a colheita de $10 \mathrm{cc}$; prova de Stookey mostrando bloqueio parcial do canal raqueano; líquido levemente turvo; 96 leucócitos por $\mathrm{cm}^{3}$ (linfócitos $85 \%$; monócitos $15 \%$ ); proteínas $410 \mathrm{mg} / 100 \mathrm{ml}$; cloretos $652 \mathrm{mg} / 100 \mathrm{ml}$; glicose $8 \mathrm{mg} / 100 \mathrm{ml}$; reação de Pandy fortemente positiva; reação de Takata-Ara positiva tipo misto. o estado do paciente piorou rápidamente, com aparecimento de confusão mental. Tendo em vista o quadro clínico e liquórico foi suspeitada a ocorrência de carcinomatose meníngea, sendo positiva a pesquisa de células neoplásicas no LCR (fig. 1). Dois dias depois de ter sido feito o diagnóstico o doente apresentou episódio de insuficiência circulatória periférica que não respondeu à terapêutica, ocorrendo o óbito, por parada cardio-respiratória, em 21-1-1969.

Necrópsia - Neoplasia vegetante no antro gástrico com metástases ganglionares, infiltração no peritônio e nos plexos sacro e lombar, em ambas suprarenais e nas meninges espinais. O exame macroscópico da medula revelou aumento do volume e da consistência em sua porção tóraco-abdominal; os cortes transversais revelaram a presença de tecido branco e homogêneo preenchendo o espaço sub-aracnóideo e, em alguns pontos, aderido à dura-mater. o exame microscópico da neoplasia revelou tratar-se de carcinoma papilifero. Cortes da medula espinal mostraram a presença de metástases que se localizavam na periferia de raízes nervosas e na luz de linfáticos (fig. 2). Em alguns pontos o tecido neoplásico penetrava na espessura da dura-mater. Foram atingidas as raízes nervosas ventrais e dorsais, assim como a própria medula (a partir da pia-mater) em suas duas faces; algumas raízes raqueanas também apresentavam infiltração neoplásica em seu trajeto extra-dural (fig. 3). 0 tecido neoplásico era constituído por cordōes celulares e glândulas atípicas. As células neoplásicas eram do tipo epitelial, com núcleos grandes, vesiculosos, polimorfos, com nucléolos e mitoses atípicas; o citoplasma era claro e eosinófilo. No tecido nervoso medular existiam áreas com processos degenerativos isquêmicos. 


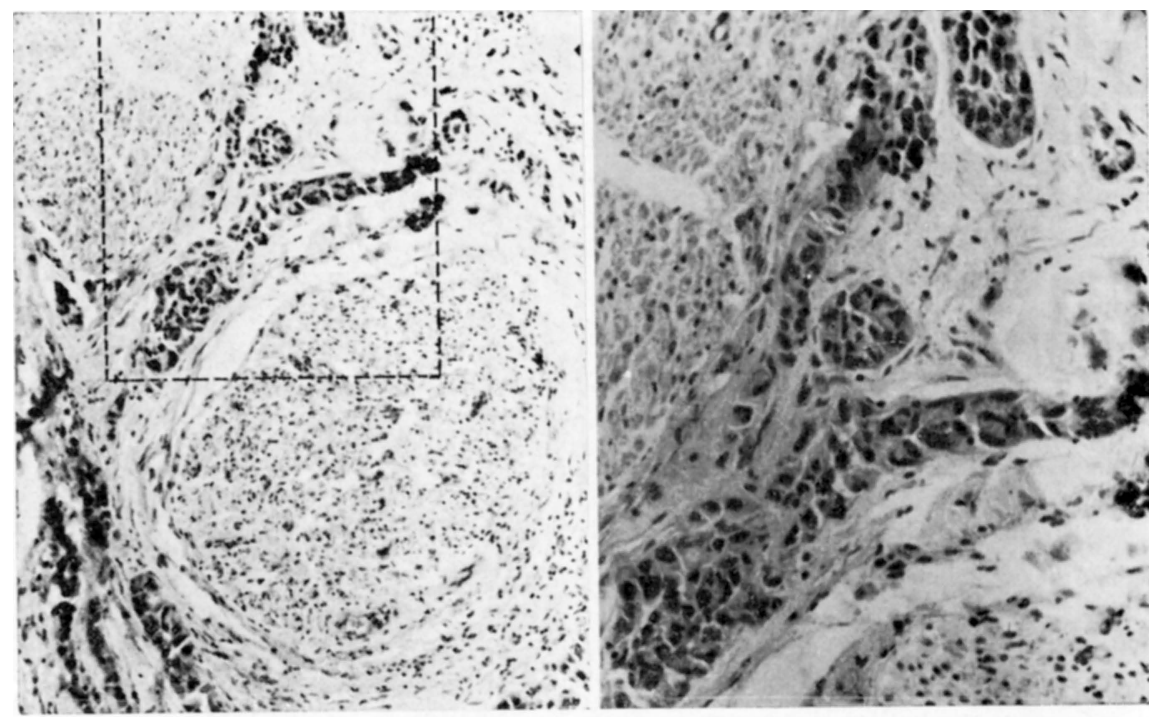

Fig. 3 - Caso J.M. À esquerda, corte de raiz raqueana no trajeto extradural com metástases na luz de linfáticos periféricos; à direita, aumento maior da parte assinalada.

\section{COMENTARIOS}

No presente caso chama atenção o longo tempo de evolução de um carcinoma de alta malignidade com sinais de comprometimento da função intestinal e do estado geral. Com 12 meses de doença o paciente foi submetido a estudo clínico, radiológico e laboratorial, sem que fôsse possivel estabelecer diagnóstico certo; após 18 meses de evolução ocorreram sinais de comprometimento neurológico, indicando acometimento de raizes espinais e de nervos cranianos, agravando-se o quadro ràpidamente com distúrbios da funcionalidade encefalomedular, ocorrendo o óbito, por paralisação cardio-respiratória no $18 .^{\circ}$ mês de evolução.

Quanto ao quadro liquórico, dois aspectos merecem ser comentados: a pleocitose e a hipoglicorraquia. Os dados de literatura mostram que é quase constante a ocorrência de reação inflamatória das meninges secundária à presença de infiltrado neoplásico. A hipoglicorraquia também é freqüentemente registrada. O achado de células neoplásicas no LCR resolveu definitivamente o problema do diagnóstico. Atendendo à simplicidade técnica, julgamos que sua pesquisa deveria ser feita como rotina em todos os casos em que houvesse comprometimento meningorradicular de evolução aguda ou sub-aguda nos quais coubesse a suspeita de processo tumoral. Elas foram encontradas, em um caso, no LCR ventricular ${ }^{5}$.

A necrópsia foi particularmente surpreendente, tendo em vista o enorme tamanho da neoplasia gástrica (mais ou menos $10 \mathrm{~cm}$ de diâmetro) e a metastização maciça para ambas as adrenais; esta era tão intensa que uma insuficiência adrenocortical aguda poderia ter contribuído para o qua- 
dro final de insuficiência circulatória periférica. Ao exame macroscópico só foi assinalado leve espessamento das meninges espinais; à microscopia, o quadro de comprometimento meníngeo era bastante evidente, com englobamento das raizes raqueanas e invasão da medula espinal. Ao nível do corno anterior da intumescência lombar, existiam imagens de degeneração axônica. Os vasos linfáticos da bainha conjuntiva dos nervos radiculares estavam difusamente infiltrados. Este achado e a infiltração neoplásica no retroperitôneo e plexos lombar e sacro, sugerem ter sido a via linfática, o meio de invasão do espaço sub-aracnóideo.

\section{R E S U M O}

Registro de um caso de carcinomatose meníngea. O diagnóstico foi estabelecido pela evolução e pelo encontro de células neoplásicas no líquido cefalorraqueano. A necrópsia mostrou existir carcinoma papilífero do estômago, com metástases nas supra-renais, no espaço retroperitonial, no espaço sub-aracnóideo comprometendo raízes nervosas, nas paredes e na luz de vasos linfáticos, na espessura da dura-mater e no tecido nervoso medular.

\section{S U M M A R Y}

Carcinomatosis of the meninges: a case report.

A case of carcinoma of the meninges, diagnosed through the clinical picture and the finding of neoplastic cells in the cerebrospinal fluid is reported. The post-mortem examination showed a papillary carcinoma of the stomach with metastases in the retroperitoneal space, in the subarachnoideal space infiltrating the spinal roots, in the lymphatic vessels of the nerve trunks, in the dura-mater and the spinal cord.

\section{R E F E R N C I A S}

1. AITA, J. A. - Neurologic Manifestations of General Diseases. Charles C. Thomas, Springfield (Illinois), 1964, p. 230.

2. BENSON, D. F. - Intramedullary spinal cord metastasis. Neurology (Minneapolis) 10:281, 1960 .

3. FISCHER-WILLIAMS, M.; BOSANQUET, D. F. \& DANIEL, M. P. - Carcinomatosis of the meninges. Brain 78:42, 1955.

4. MATTOSINHO-FRANÇA, L. C. \& SPINA-FRANÇA, A. - Método de Papanicolau e pesquisa de células neoplásicas no liquido cefalorraqueano. Rev. paul. Med. (São Paulo) 67:203, 1965.

5. RICCIARDI-CRUZ, O. - Carcinomatose das meninges. Arq. Neuro-Pesiquiat. (São Paulo) 17:61, 1959.

6. STAM, F. C. - Leptomeningeal carcinosis. Psychiat. Neurol. Neuro-chir. (Amsterdam) 63:2, 1960 .

Departamento de Neurologia - Faculdade de Medicina da Universidade de São Paulo - Caixa Postal 3461 - São Paulo, SP - Brasil. 